much concern to medical politics. The village worker suggested above is still unacceptable to many doctors and their professional organizations. In rural Punjab research has shown that three-quarters of the health care is provided through local people who have learnt to give injections and practise traditional medicine in response to the people's need. A proposal by the Indian Government to recognize and provide training for these people in such subjects as nutrition was defeated by the medical lobby. Other countries have medical professions no more liberal than India. Effective services in rural areas continue to be blocked by city-based doctors and nurses striving after and passing laws to maintain and improve training of personnel and standards of health care for the élite who live in their cities-standards of care and qualifications which are out of the reach of the rural people both now and in the foreseeable future.

\section{References}

1 Bryant, J. H., Health and the Developing World. Ithaca, N.Y., Cornell University Press, 1969.

2 Cook, R. J., Fournal of Tropical Paediatrics and Environmental Child Health, 1971, 17, 15.

3 Morley, D., Transactions of the Royal Society of Tropical Medicine and Hygiene, 1973, 67, 155

4 Chi Wen, Lancet, 1974, i, 976

5 Behrhorst, C. Personal communication, 1974.

- Shah, P. Personal communication, 1973.

'Shakir, A., and Morley, D., Lancet, 1974, 1, 758.

8 Morlev, D., Paediatric Priorities in the Developing World. London, Butterworths, 1973.

\title{
Some Aspects of Childhood Malnutrition as a Public Health Problem*
}

\author{
J. C. WATERLOW
}

British Medical Fournal, 1974, 4, 88-90

\section{Types of Malnutrition}

Jamaica has made substantial advances in social and economic development since its independence in 1963. Nevertheless, severe primary malnutrition is still a common cause for admission of children to the paediatric wards. ${ }^{1}$ It is obvious, however, that those who come to hospital represent only a small proportion of the children who are moderately or even severely malnourished. Attention is being focused more and more on malnutrition as a public health problem rather than a clinical one. The kind of questions which have to be asked are: how common is malnutrition in any given community and how severe is it? At what age and under what conditions does it occur? What happens in the long run to these malnourished children?

W.H.O. Reports suggest that in many countries up to $40 \%$ of preschool children may be regarded as malnourished. ${ }^{2}$ These statistics are based on surveys in which children are classified as malnourished according to their deficit in weight for age. The dividing line between "normal" and "malnourished" is obviously arbitrary, but is usually taken as $75 \%$ of expected standard weight for age. This arbitrary division is strictly analogous to the classification of children as obese if they are more than $120 \%$ of standard weight for age. Whether one is dealing with obesity or with malnutrition the standards used are generally derived from the mean weights and heights of healthy children in North America or Europe. The most widely used are those of Stuart and Stevenson, and of Tanner and coworkers." The problem of whether such standards are appropriate for all ethnic groups is a difficult one which cannot be discussed here. Habicht ${ }^{5}$ has recently suggested that, whatever differences there may be in final stature, there is no evidence for ethnic differences in growth potential during the early years of life. In his view, it is justifiable to apply the norms of developed countries to other communities where malnutrition is common.

- Based on a paper given at the Annual Clinical Meeting of the B.M.A. and the Medical Association of Jamaica, Kingston, Jamaica, April 1974.

London School of Hygiene and Tropical Medicine, London WC1E $7 \mathrm{HT}$

J. C. WATERLOW, M.D. F.R.C.P. Professor of Human Nutrition
Previous papers have contended that weight for age is a very misleading criterion of nutritional state. ${ }^{\circ} \mathrm{A}$ deficit in weight for age may be produced in two different ways or by a combination of them (fig. 1). The two children A and B are surely quite different clinically and physiologically, and should not be classified as if they were the same. We need different words to describe these two different states, and I have suggested elsewhere ${ }^{7}$ that the child who is underweight for height might be described as wasted, and the child who is below normal height for age might be called retarded or stunted. Naturally in practice many malnourished children are both wasted and stunted. A simple system has been proposed by which a child can be classified according to the degree of both wasting and stunting.

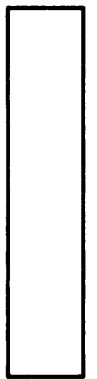

Normal

$\begin{array}{lr}\text { Age, years } & 1 \\ \text { Weight, kg } & 10 \\ \text { Height, cm } & 75 \\ \% \text { Weight/age,years } & 100 \\ \% \text { Height/oge,years } & 100 \\ \% \text { Weight/height } & 100\end{array}$

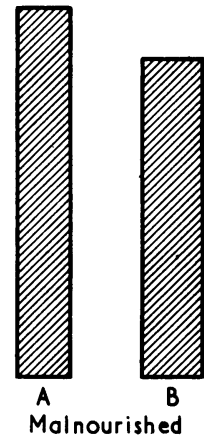

$\begin{array}{rr}1 & 1 \\ 7 & 7 \\ 75 & 65 \\ 70 & 70 \\ 100 & 87 \\ 70 & 100\end{array}$

FIG. 1-Comparison between two hypothetical children with the same deficit in weight for age to illustrate the difference between "wasting" and "stunting".

TABLE I-Grading of Deficit in Height and Weight

\begin{tabular}{c|c|c}
\hline Grade & Initial grading & Revised grading \\
\hline 0 & $>95 \%$ & $>95 \%$ \\
1 & $-87.5 \%$ & $-90 \%$ \\
2 & $<80 \%$ & $<85 \%$ \\
3 & & $<85 \%$ \\
\hline
\end{tabular}


I have suggested that stunting might be divided into three grades of deficit in height for age. ${ }^{6}$ In a later paper ${ }^{1}$ I suggest that the particular cut-off points chosen were not the most appropriate, and a revised grading was proposed." In both cases the expected height for age was that of the Harvard standards (table I).

Examination of published data from several developing countries $^{8}$ has shown that between the ages of 1 and 2 years wasting-that is, deficit in weight for height-is common and may be severe. As the child gets older the degree of wasting tends to decrease. Though many children are still significantly underweight for their age by the age of 3-4 years, this is largely because of stunting rather than wasting. In other words, they are retarded in linear growth, but of more or less normal weight for height. For example, in one African country, where childhood malnutrition is a serious problem and the mortality below the age of 5 very high, most of the children over 3 years old were within normal limits of weight for height, and some were even mildly overweight (table II). Yet if classified by weight for age many of these small rather fat children would have been called malnourished. Thus the pattern of malnutrition tends to change during the first five years of life, and it is quite incorrect to treat preschool malnutrition as if it were an entity. TABLE II-Percentage of Children Between 2 and 5 Years Old in Each Grade of
Expected Weight for Height (Harvard standards). (Data from a survey in Central Africa, by courtesy of H. F. L. Burgess)

\begin{tabular}{c|c|c|c|c|c|c}
\hline Age (months) & $\begin{array}{c}\text { No. of } \\
\text { children }\end{array}$ & $<80$ & $80+$ & $90+$ & $100+$ & $110+$ \\
\hline $23-35$ & 45 & 11 & 45 & 24 & 16 & 4 \\
$36-47$ & 80 & $7 \cdot 5$ & 21 & 39 & 40 & $2 \cdot 5$ \\
$48-59$ & 77 & 0 & 23 & 36 & 32 & 8 \\
\hline
\end{tabular}

It may seem that this emphasis on stunting and the deficit in height may be in conflict with the principles of Morley's weight charts, which show the progression of weight in relation to age. There is, however, no real conflict, because the objectives are different, though complementary. The purpose of weight charts is to follow an individual child in a clinic, and if its rate of weight gain slows down, this is an indication for action. At the onset of malnutrition the treatment is the same-at least as far as we know at present-whether the cause of faltering in weight is wasting or stunting. Usually, of course, it is both.

The purpose of the classification which I have proposed is to help in assessing the situation and to serve as a guide to action at the public health or community level. Figure 2, which I have called an action diagram, ${ }^{8}$ is an example derived from a survey

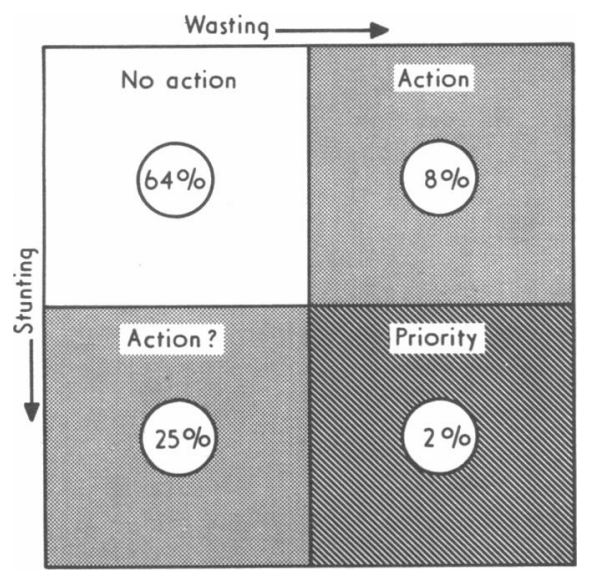

FIG. 2-“Action diagram" derived from measurements of weights and heights. Children were classified according to the degree of wasting and stunting. ${ }^{7}$ Horizontal axis: severity of wasting. Vertical axis: severity of stunting. In each case the dividing lines separate grades $0+1$ (normal and mild) from grades $2+3$ (moderate and severe). in an African country where there are thought to be serious nutritional problems. The state of two-thirds of the children (top left) may be considered reasonably satisfactory; a very small proportion (bottom right) are so seriously malnourished that they need urgent treatment, probably in hospital. A larger proportion (top right), about $10 \%$, are moderately or even severely wasted, and clearly need nutritional rehabilitation. The real problem arises over the $25 \%$ of children (bottom left) who are stunted but not significantly wasted. Is any kind of nutritional intervention needed for them? Since it seems that this group is usually a large one in undernourished communities, the answer is of great importance for public health.

If one defines malnutrition operationally as a state of ill-health which can be improved by qualitative or quantitative changes in the diet, the question is whether these children are, at the present time, malnourished. As table II shows, some of these stunted children tend to be overweight for their height, and increasing their food intake might simply cause obesity. Though there is very little information available, the long-term studies of Graham and coworkers ${ }^{9}$ suggest that if severely retarded children are returned to a good environment they may show a significant catch-up in height over a period of years. Nevertheless, to be taller is not necessarily to be healthier. At the M.R.C. Unit in Jamaica it has been the practice to regard a malnourished child as "cured" when he has reached his normal weight for height. At this stage most of the children are still underweight for their age, because they are stunted, but clinically they appear to be healthy, and this is borne out by the very low rate of recurrence after discharge from hospital. I mysef do not regard such children as malnourished just because their weight for age is low.

\section{Long-term Effects of Malnutrition}

It is obviously very important to distinguish between malnutrition and handicap. What are the long-term after-effects of malnutrition in early life? On the physical side very little is known. Animal experiments suggest that marginal malnutrition and retardation of growth may in fact prolong life, ${ }^{10}$ but, of course, what matters is not the length of life but its quality. In the last ten years or so attention has mainly been concentrated on the effects of malnutrition on the brain and on mental development. Both the biochemical and the psychological aspects of this subject have been reviewed in a number of excellent symposia.11-14 The study of this problem in man is made immensely difficult because malnutrition is accompanied by other factors which affect a child's development, such as repeated infections and a poor social environment.

This is a very large subject and I shall only refer to one study because it was done in Jamaica. This was an investigation organized in 1970 by the late Professor Herbert Birch and Dr. Stephen Richardson of New York, together with Professor Jack Tizard of London, in which a determined effort was made to separate the effects of malnutrition from those of other aspects of life in poor families. Eighty boys were located who, four to eight years previously, had been treated for severe malnutrition in the M.R.C. Unit or the paediatric ward of the university hospital. These formed the index group. A second group consisted of the male sibs of the index cases nearest to them in age. A third group, called the comparison group, consisted of boys of the same age as the index cases attending the same class in the same school.

These three groups of children were brought to the unit for physical, neurological, and psychological examination. The I.Q. of the previously malnourished boys was on average lower than that of their sibs, and the sibs were worse than the comparison group. This result was to be expected from previous studies in other countries. ${ }^{15}$ Intellectial capacity is, of course, not the only quality necessary for successful performance in life. The behaviour of the children in school was graded by the teacher according to criteria such as their capacity for attention, fo 
interaction, and the extent to which they were liked by other children and got on well with them. The teachers did not know which children belonged to which group. Figure 3 shows very strikingly the poor rating of the index children.

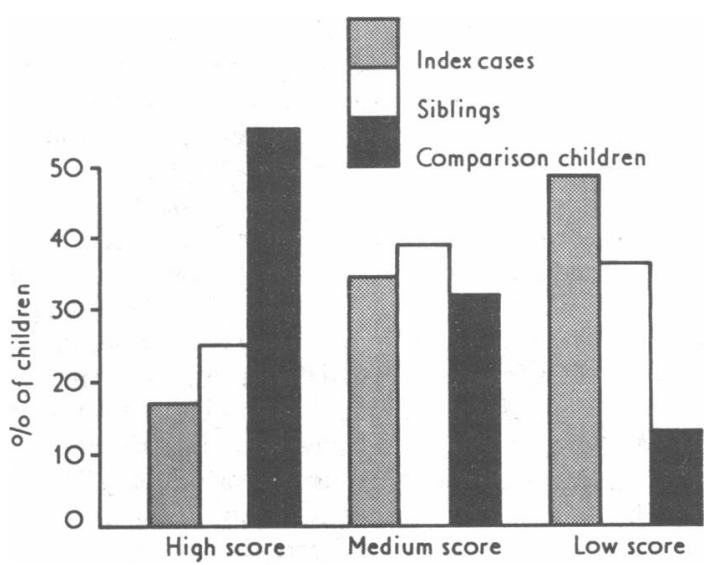

FIG. 3-Behaviour in school of children previously malnourished comparer with sibs and controls.

These results suggest a relation between performance and an episode of malnutrition in infancy, but the social concomitants of malnutrition must also be considered. On the basis of a detailed questionnaire about the circumstances of each family Richardson constructed a system of scoring for the amount of social stimulation received by each child. ${ }^{18}$ The combination of malnutrition and poor stimulation is extremely bad, and probably a low level of stimulation makes quite an important contribution to the deficit in I.Q.

On the other side, it would be unjustifiable to conclude from these results that good stimulation can repair damage caused by malnutrition. All one can say is that, even when malnutrition has been very severe, stimulation can still have an important effect. I think that stimulation may be relatively more important, and physical damage to the brain less important, in determining the outcome in the much larger group of stunted moderately malnourished children discussed in the first part of this paper. If this is so, perhaps it gives grounds for optimism.

Another factor which is partly nutritional, partly social, is the effect of a low energy intake. In Jamaica, as in many other developing countries, the diet of preschool children is usually more deficient in energy than in protein. ${ }^{17}$ Anyone who has seen these children sitting apathetically in the yard doing nothing very much will appreciate how this reduction in exploratory activity must affect their mental development.

\section{Conclusions}

I draw two conclusions from the results presented here.

In public health programmes of nutritional intervention, all preschool children up to the age of 5 years should not be treated as if they were the same. If it is a question of providing supplementary food, priority should be given to children below the age of 2 years, and probably to women in the last trimester of pregnancy. ${ }^{18}$ Older children, of course, need a food intake which will meet their requirements for energy, protein, and other nutrients, but attempts at nutritional "rehabilitation" of the stunted child are unlikely to accomplish very much.

Whether or not it is true that malnutrition causes permanent damage to the brain, clearly a child's mental and behavioural development is sensitive to social factors operating throughout the growing period. In a community where there are many stunted children the emphasis has to be on social rather than purely nutritional rehabilitation. This is, of course, more easily said than done.

\section{References}

1 Ashworth, A., and Waterlow, J. C., Nutrition in famaica, 1969-70. Department of Extramural Studies, University of the West Indies, 1974.

2 Bengoa, J. M., W.H.O. Chronicle, 1974, 28, 3.

3 Stuart, H. C., and Stevenson, S. S., in Textbook of Pediatrics, ed. W. E. Nelson, 7th edn., p. 12. Philadelphia, Saunders, 1959.

4 Tanner, J. M., Whitehouse, R. H., and Takashi, M., Archives of Disease in Childhood, 1966, 41, 613.

5 Habicht, J-P., et al., Lancet, 1974, 1, 611.

Waterlow, J. C., British Medical fournal, 1972, 3, 566.

7 Waterlow, J. C., Lancet, 1973, 2, 87.

8 Waterlow, J. C., and Rutishauser, Ingrid, H. E., Malnutrition in Man in Symposia of Swedish Nutrition Foundation, XII. Stockholm, Almqvist and Wiksell, 1974

- Graham, G. G., and Adrianzen, T. B., Fohns Hopkins Medical fournal 1972, 131, 204.

10 Ross, M. H., Fournal of Nutrition, 1969, 97, 555.

11 Malnutrition, Learning and Behaviour, ed. N. S. Scrimshaw and J. E. Gordon. Cambridge, Mass., M.I.T. Press, 1968.

12 C.I.B.A. Foundation Symposium, Lipids, Malnutrition and the Developing Brain. Amsterdam, Elsevier, 1972.

13 Nutrition the Nervous System and Behaviour, Scientific Publication No. 251. Washington D.C., Pan American Health Organization, 1972.

14 Symposia of the Swedish Nutrition Foundation XII, Early Malnutrition and Mental Development. Stockholm, Almqvist and Wiksell, 1974.

15 Monckeberg, F., in Nutrition, the Nervous System and Behaviour, Scientific Publication No. 251, p. 48. Washington, D.C., Pan American tific Publication No. 251,

16 Richardson, S. A., in Nutrition, the Nervous System and Behaviour, Scientific Publication No. 251, p. 101. Washington D.C., Pan American Health Organization, 1972.

17 Fox, H. C., Campbell, V. S., and Lovell, H. C., Archivos Latinamericanos de Nutricion, 1968, 18, 81.

18 Habicht, J-P., et al., Nutrition Reports International, 1973, 7, 533.

19 Birch, H. G., and Richardson, S. A., in Nutrition, the Nervous System and Behaviour, Scientific Publication No. 251, p. 64. Washington D.C., Pan American Health Organization, 1972. 